\title{
Relationships of Psychological Constructs with Physical Activity in Korean University Students
}

\author{
In Kyoung Park', Sung Min Oh², Youngho Kim', Soojin Kang ${ }^{1 *}$ \\ ${ }^{1}$ Department of Sport Science, Seoul National University of Science and Technology, Korea \\ ${ }^{2}$ College of Sport Science, Sungkyunkwan University, Korea
}

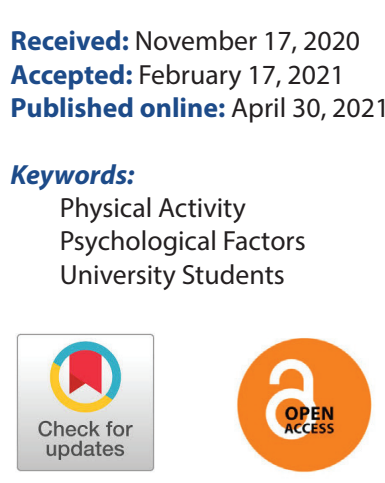

\section{ABSTRACT}

\begin{abstract}
OBJECTIVES The purposes of this study were to investigate differences in health risk perception, exercise knowledge, self-efficacy, exercise adherence, pros, cons, and physical activity by gender and the level of exercise participation and to identify the influences of the psychological constructs on physical activity in Korean university students.

METHODS A total of 495 university students ( 213 males, 282 females; age $=20.55$ years, $S D=2.01$ ) from three universities located in Seoul, Incheon, and Gyeonggi-do voluntarily participated in this study. In order to measure physical activity and its related psychological variables, five standardized Korean questionnaires were applied. Data were analyzed by descriptive analysis, MANOVAs, and multiple regression analysis.

RESULTS It was confirmed that there were some partial differences in psychological factors and physical activity (total, intermediate/high intensity) depending on the gender and level of participation in sports of the students. Also there were differences in factors that affected their physical activities by gender and level of participation in sports.

CONCLUSIONS It needs to be continued in order to gain more empirical knowledge from evidence-based investigations applying the theory-based interventions with some other variables such as gender, age and the level of physical activity participation.
\end{abstract}

(c) The Asian Society of Kinesiology and the Korean Academy of Kinesiology

\section{Introduction}

University students are not easily aware of the need for healthy behaviors including physical activity, since they easily believe that their physical fitness and health are generally at their best [1]. However, once formed habits are more likely to persist, so it is important to help acquire the right behavioral patterns early in adulthood and make them as a standardized routine [2].

What factors influence physical activity among university students? Generally, it is widely accepted that this enquiry has

*Correspondence: Soojin Kang, Department of Sport Science, Seoul National University of Science and Technology, 232 Gongneung-Dong Nowon-Gu, Seoul, Korea; Tel: +82-02-970-6369; Fax: +82-02-970-9763; E-mail: eostm2000@naver.com been explained on the basis of various exercise psychology theories such as health belief model, theory of planned behavior, self-efficacy theory, self-determination theory, and transtheoretical model in exercise psychology. The cognitive factors affecting exercise behavior in these theories are exercise knowledge [3,4], disease sensitivity [5] and health risk perception [2,6]. psychological factors at the emotional level are the most frequently used exercise self-efficacy [7], physical activity pro and cons [8], and exercise adherence intention [9], also other factors such as movement, attitude, exercise image, enjoyment, self-schema affect personal physical activity [10].

Exploring the major factors involved in exercise and physical activity and revealing the relationship between 
them are important in understanding the phenomena of the study and in finding methods to lead to change. Based on these studies, programs for promoting physical activity have been presented and implemented to overcome the lack of exercise and physical activity. The early stages mainly provide information about physical activity to change awareness and cognitive information that informs the effects. They also show patterns such as providing decisions and actions while practicing physical [11,12].

The main strategies are similar when applied to adolescences [13], university students [11], and office workers [14], and each study is reported to have a corresponding effect. However, a recent study by Park and Kim [2] showed that some health risk perception factors and exercise knowledge of university students were not affected by physical activities, and these results are the same as a study that shows that adolescences and university students' health knowledge and participation in sports activities are not related $[15,16]$. Middle-aged adults, on the other hand, are reported to have a health risk perception or exercise knowledge affecting their physical activities $[17,18]$. In other words, exercise knowledge or health risk perception was valid information for middleaged adults but not affected university students at the level. In fact, university students are exposed to a lot of information through various media, so it is rare for them to be unable to exercise due to lack of information.

So, what factors influence the physical activity of university students? It is necessary to identify which factors affect the physical activity of university students unless exercise knowledge or health risk perception are not the factors that control their activity. And based on the results, it would be necessary to change the existing method in which physical activity-related information is provided in the early stages. To confirm this, we propose that the need to refine the subject's segmented characteristics to determine what factors influence their physical activities.

Although the psychological responses of the subjects vary depending on gender or level of exercise participation [19], many Korean studies have been reported without considering the variables. For example, studies to explore psychological factors affecting university students' physical activities measure the gender or level of exercise participation of subjects, but they are not often analyzed by classification with the above factors. Then, the influence factors of all university students can be identified, but it is difficult to identify the difference between male and female students and those who do not exercise and those who practice regular exercise. It is not appropriate to plan a practical intervention strategy for them.

The purposes of this study were to investigate differences in health risk perception, exercise knowledge, self-efficacy, exercise adherence, pros, cons, and physical activity by gender and the level of exercise participation and to identify the influences of the psychological constructs on physical activity in Korean university students.

\section{Methods}

\section{Participants}

A total of 495 university students ( 213 males, 282 females; Mage $=20.55$ years, $S D=2.01)$ from three universities located in Seoul, Incheon, and Gyeonggi-do voluntarily participated in this study. Dissemination sources of participant recruitment included: (a) a press release issued through the universities, (b) recruitment flyers posted on university websites, and (c) announcement made through classes. In the initial stage of this study, it was emphasized that current exercisers, nonexercisers, and those not even interested in exercising were encouraged to participate. Then 520 participants who gave their consent completed the survey form. Through these procedures, 495 (95.2\%) of the questionnaires were successfully included in the study. The remaining 35 (4.8\%) of the participants were disqualified because they failed complete the survey form. The study was approved by the Institutional Review Board of Seoul National University of Science and Technology.

\section{Instruments}

Physical activity

The Korean version of the International Physical Activity Questionnaires (IPAQ) developed by World Health Organization was used to measure the level of physical activity [20]. The reliability of the Korean version of the IPAQ-SF was validated; the Spearman Rho coefficients and kappa values of the test-retest reliability were $0.43-0.65$ and $0.37-0.62$, 
respectively [21]. This study used total physical activity(PA) including leisure time PA and nonleisure time PA, and then PA energy expenditure was estimated using the metabolic equivalent task (MET). An absolute MET value was assigned for walking, moderate, and vigorous intensity (3.3, 4.0, and 8.0 METs, respectively). The amount of weekly PA at each intensity level was calculated by multiplying the minutes spent on specific intensity per week by absolute MET values assigned to each category of PA intensity. Energy expended per week at all three PA intensity levels was summed up to calculate the total energy expended. The process for calculating total weekly PA was described in detail in our previous study [22]. According to Pate et al., 600METs-min/wk was regarded as the minimum recommended total PA per week; therefore, those engaging in less than 600METs-min/wk were defined as sedentary. Total energy expended per week was categorized into six categories by multiples of $600 \mathrm{METs}-\mathrm{min} / \mathrm{wk}$ : $0 \leq$ to $<600,600 \leq$ to $<1200,1200 \leq$ to $<1800,1800 \leq$ to $<3000,3000 \leq$ to $<6000$, and $\geq 6000 \mathrm{METs}-\mathrm{min} / \mathrm{wk}$.

\section{Exercise Knowledge}

The exercise knowledge questionnaire developed Morrow and the colleagues [23] was revised in Korean and applied in the study [17]. Exercise knowledge was considered healthrelated exercise knowledge by combining the contents of exercise knowledge for health promotion and questions about the relationship between lack of exercise and disease. In this scale, health related knowledge was assessed using 10-item, dichotomous scale with rating " 1 "” on the correct answer and " 0 " on the wrong answer. The higher the total score, the higher the health-related exercise knowledge.

\section{Health Risk Perception}

The self and other risk judgments profile developed by Whalen and the colleagues [24] was revised into Korean to measure participants' health risk perceptions [25]. This revised questionnaire measured the health risk perception directly related to physical inactivity, such as cardiovascular disease, diabetes, depression, obesity and various cancers with 7-point response rates range from 1 (very unlikely) to 7 (very likely) [2].
This measure has three subscales with 25 negative healthrisk events individuals might experience in their lifetime (9 items for general health, 9 items for lifestyle, and 7 items for environment). The study participants were asked to indicate how they perceived their likelihood of encountering various health risks (i.e., cancer and smoking etc.) with 7 -point response rates range from 1 (very unlikely) to 7 (very likely). The alpha reliabilities by domain were .90 for self-risk perception, .89 for other-risk perception, and .90 for significant other-risk perception $\left(\mathrm{KMO}=.86, x^{2}=7824.71\right.$, $d f=105, \mathrm{p}<.001)$.

\section{Exercise Self-efficacy}

Exercise Self-efficacy Scale, developed by Bandura was revised for the Korean Version and applied in this study [26]. The questionnaire consists of 6 items with a 5-point Likert scale ranging from 1 (cannot do) through intermediate degrees of assurance such as 3 (moderately certain can do) to complete assurance, 5 (certain can do). Individuals rated in one space under a column labelled 'confidence' how confident they were that they could perform exercise routines regularly (three or more times a week) under the various circumstances. Cronbach coefficient alpha was calculated as a measure of internal consistency for the scale, and a standardized alpha of .72 was obtained. In addition, 2-week test-retest reliability was performed as a measure of instrument stability, resulting in a reliability coefficient of $.86\left(\mathrm{KMO}=.77, x^{2}=557.56, d f=15\right.$, $\mathrm{p}<.001)$.

\section{Pros and cons}

Pros and cons scale is a self-administered 10-items questionnaire, developed by Plotnikoff, Blanchard, Hotz, and Rhodes [27] was revised for the Korean version [28], and adopted in the study. The scale consists of the two subscales (pros and cons with 5 items each). By using the 5-point Likert scale, students were required to answer based on their preference from "not at all important (1)" to "extremely important (5)". Two main components of the decisional balance scale are pros and cons, which represent the positive and negative aspect of individual's behavioral changes. Cronbach coefficient alpha was calculated as a measure of 
internal consistency for the scale, and a standardized alpha was .79 for pros and .70 for cons. In addition, 2-week testretest reliability was performed as a measure of instrument stability, resulting in a reliability of pros was .89 and cons was $.91\left(\mathrm{KMO}=.75, x^{2}=1284.38, d f=45, \mathrm{p}<.001\right)$.

\section{Exercise Adherence}

The exercise adherence questionnaire developed by Ajzen [29] was revised into Korean and used in the study [30]. The questionnaire consists of 7-point Likert scale ranging from 1 (not at all) to 7 (very much). Cronbach coefficient alpha was calculated as a measure of internal consistency for the scale, and a standardized alpha was $.83\left(\mathrm{KMO}=.70, x^{2}=600.17, d f=3\right.$, $\mathrm{p}<.001)$.

\section{Statistical Analysis}

After the study participants were recruited, face-validity was checked through expert meetings on the contents and components of the questionnaire. A preliminary survey was also conducted on 15 participants to identify understanding of the questions and item goodness-of-fit. After explaining the purpose of the survey to the subjects, the questionnaire was conducted with the signature of the study agreement to participate voluntarily.

The data was analyzed with SPSS 23.0 and the descriptive statistics was performed to check the average, standard deviation, skewness, kurtosis and frequency of response of the questions for the questions. In addition, before analyzing the main research questions of the study, exploratory factor analysis and reliability analysis were performed to verify

Table 1. Differences in physical activity and psychological variables by gender and the level of exercise participation

\begin{tabular}{|c|c|c|c|c|c|c|c|c|c|c|c|c|}
\hline \multirow[b]{2}{*}{ Variables } & & \multirow[b]{2}{*}{$n$} & \multirow[b]{2}{*}{1} & \multirow[b]{2}{*}{2} & \multirow[b]{2}{*}{3} & \multirow[b]{2}{*}{4} & \multirow[b]{2}{*}{5} & \multicolumn{3}{|c|}{6} & \multicolumn{2}{|l|}{ 7(METs) } \\
\hline & & & & & & & & self & others & $\begin{array}{l}\text { Significant } \\
\text { other }\end{array}$ & $\begin{array}{l}\text { moderate and } \\
\text { strenuous }\end{array}$ & Total $^{\mathrm{a}}$ \\
\hline \multirow{4}{*}{$\begin{array}{c}\text { M } \\
\mathrm{a} \\
\mathrm{I} \\
\mathrm{e}\end{array}$} & A & 48 & $\begin{array}{l}2.77 \\
(.68)\end{array}$ & $\begin{array}{l}3.96 \\
(.71)\end{array}$ & $\begin{array}{l}2.61 \\
(.56)\end{array}$ & $\begin{array}{l}3.47 \\
(1.32)\end{array}$ & $\begin{array}{l}20.96 \\
(3.28)\end{array}$ & $\begin{array}{l}4.39 \\
(1.51)\end{array}$ & $\begin{array}{l}4.33 \\
(1.53)\end{array}$ & $\begin{array}{l}4.60 \\
(1.32)\end{array}$ & $\begin{array}{l}225.00 \\
(573.43)\end{array}$ & $\begin{array}{l}1103.63 \\
(1003.45)\end{array}$ \\
\hline & B & 78 & $\begin{array}{l}2.97 \\
(.62)\end{array}$ & $\begin{array}{l}3.89 \\
(.75)\end{array}$ & $\begin{array}{l}2.46 \\
(.77)\end{array}$ & $\begin{array}{l}4.52 \\
(1.18)\end{array}$ & $\begin{array}{l}20.95 \\
(3.14)\end{array}$ & $\begin{array}{l}4.35 \\
(1.38)\end{array}$ & $\begin{array}{l}4.75 \\
(1.03)\end{array}$ & $\begin{array}{l}4.71 \\
(1.07)\end{array}$ & $\begin{array}{l}915.38 \\
(1174.34)\end{array}$ & $\begin{array}{l}1953.19 \\
(1387.87)\end{array}$ \\
\hline & $C$ & 87 & $\begin{array}{l}3.36 \\
(.60)\end{array}$ & $\begin{array}{l}4.21 \\
(.51))\end{array}$ & $\begin{array}{l}2.26 \\
(.67)\end{array}$ & $\begin{array}{l}4.88 \\
(1.08)\end{array}$ & $\begin{array}{l}20.51 \\
(2.81)\end{array}$ & $\begin{array}{l}4.72 \\
(1.35)\end{array}$ & $\begin{array}{l}4.94 \\
(.94)\end{array}$ & $\begin{array}{l}5.07 \\
(.95)\end{array}$ & $\begin{array}{l}2951.45 \\
(2506.67)\end{array}$ & $\begin{array}{l}3659.24 \\
(2808.72)\end{array}$ \\
\hline & Total & 213 & $\begin{array}{l}3.08 \\
(.66)\end{array}$ & $\begin{array}{l}4.04 \\
(.67)\end{array}$ & $\begin{array}{l}2.40 \\
(.69)\end{array}$ & $\begin{array}{l}4.40 \\
(1.35)\end{array}$ & $\begin{array}{l}20.77 \\
(3.04)\end{array}$ & $\begin{array}{l}4.51 \\
(1.41)\end{array}$ & $\begin{array}{l}4.74 \\
(1.15)\end{array}$ & $\begin{array}{l}4.84 \\
(1.10)\end{array}$ & $\begin{array}{l}1604.25 \\
(2120.78)\end{array}$ & $\begin{array}{l}2462.72 \\
(2296.13)\end{array}$ \\
\hline \multirow{4}{*}{$\begin{array}{c}\mathrm{F} \\
\mathrm{e} \\
\mathrm{m} \\
\mathrm{a} \\
\mathrm{I} \\
\mathrm{e}\end{array}$} & A & 97 & $\begin{array}{l}2.57 \\
(.55)\end{array}$ & $\begin{array}{l}3.84 \\
(.69)\end{array}$ & $\begin{array}{l}2.88 \\
(.49)\end{array}$ & $\begin{array}{l}3.34 \\
(1.71)\end{array}$ & $\begin{array}{l}21.37 \\
(2.82)\end{array}$ & $\begin{array}{l}4.22 \\
(1.33)\end{array}$ & $\begin{array}{l}4.36 \\
(1.26)\end{array}$ & $\begin{array}{l}4.52 \\
(1.32)\end{array}$ & $\begin{array}{l}148.04 \\
(410.44)\end{array}$ & $\begin{array}{l}1067.69 \\
(1461.78)\end{array}$ \\
\hline & B & 125 & $\begin{array}{l}2.74 \\
(.52)\end{array}$ & $\begin{array}{l}4.01 \\
(.48)\end{array}$ & $\begin{array}{l}2.60 \\
(.58)\end{array}$ & $\begin{array}{l}4.32 \\
(1.28)\end{array}$ & $\begin{array}{l}21.92 \\
(2.43)\end{array}$ & $\begin{array}{l}4.29 \\
(1.49)\end{array}$ & $\begin{array}{l}4.58 \\
(1.14)\end{array}$ & $\begin{array}{l}4.63 \\
(1.17)\end{array}$ & $\begin{array}{l}672.00 \\
(947.28)\end{array}$ & $\begin{array}{l}1470.07 \\
(1368.15)\end{array}$ \\
\hline & C & 60 & $\begin{array}{l}3.12 \\
(.57)\end{array}$ & $\begin{array}{l}3.99 \\
(.50)\end{array}$ & $\begin{array}{l}2.41 \\
(.62)\end{array}$ & $\begin{array}{l}4.85 \\
(1.21)\end{array}$ & $\begin{array}{l}21.33 \\
(2.69)\end{array}$ & $\begin{array}{l}4.09 \\
(1.51)\end{array}$ & $\begin{array}{l}4.33 \\
(1.36)\end{array}$ & $\begin{array}{l}4.52 \\
(1.41)\end{array}$ & $\begin{array}{l}1869.33 \\
(2180.40)\end{array}$ & $\begin{array}{l}2742.18 \\
(2452.21)\end{array}$ \\
\hline & Total & 282 & $\begin{array}{l}2.76 \\
(.58)\end{array}$ & $\begin{array}{l}3.95 \\
(.57)\end{array}$ & $\begin{array}{l}2.66 \\
(.58)\end{array}$ & $\begin{array}{l}4.11 \\
(1.52)\end{array}$ & $\begin{array}{l}21.61 \\
(2.69)\end{array}$ & $\begin{array}{l}4.23 \\
(1.44)\end{array}$ & $\begin{array}{l}4.46 \\
(1.23)\end{array}$ & $\begin{array}{l}4.58 \\
(1.27)\end{array}$ & $\begin{array}{l}750.14 \\
(1363.24)\end{array}$ & $\begin{array}{l}1609.23 \\
(1794.07)\end{array}$ \\
\hline \multicolumn{3}{|l|}{ gender } & $16.77^{* * *}$ & 1.75 & $10.19^{* *}$ & .88 & $7.44^{* *}$ & $4.52^{*}$ & $5.03^{*}$ & $4.40^{*}$ & $11.22^{* *}$ & $7.56^{* *}$ \\
\hline \multicolumn{3}{|c|}{$\begin{array}{l}\text { level of exercise } \\
\text { (Scheffe) }\end{array}$} & $\begin{array}{l}34.95^{* * *} \\
(a<b<c)\end{array}$ & $\begin{array}{l}4.29^{*} \\
(\mathrm{a}<\mathrm{c})\end{array}$ & $\begin{array}{l}14.85^{* * *} \\
(a>b>c)\end{array}$ & $\begin{array}{l}75.57^{* * * *} \\
(a<b<c)\end{array}$ & $\begin{array}{l}1.34 \\
-\end{array}$ & $\begin{array}{l}.39 \\
-\end{array}$ & $\begin{array}{l}3.08^{*} \\
(a<b, c)\end{array}$ & $\begin{array}{l}1.36 \\
-\end{array}$ & $\begin{array}{l}84.30^{* * *} \\
(a<b<c)\end{array}$ & $\begin{array}{l}48.15^{* * *} \\
(a<b<c)\end{array}$ \\
\hline \multicolumn{3}{|c|}{$\begin{array}{l}\text { gender } \times \\
\text { level of exercise }\end{array}$} & .03 & $3.57^{*}$ & .55 & .17 & .38 & 1.80 & 2.57 & 1.93 & $4.73^{* *}$ & 1.92 \\
\hline
\end{tabular}

${ }^{* * *} p<.001,{ }^{* *} p<.01,{ }^{*} p<.05$

A: nonexerciser; B: intermittent exerciser; C: regular exerciser; 1: self-efficacy; 2: pros; 3: cons; 4: exercise adherence;

5: exercise knowledge; 6 : health risk perception, 7 : physical activity

a Sum of mild, moderate, and strenuous physical activity

Parenthesis is standard deviation. 
validity and reliability of the study instruments. Then, MANOVAs were conducted to identify differences in exercise knowledge, health risk perception, exercise self-efficacy, physical activity(PA) pros and cons, exercise adherence, and physical activity by gender and level of exercise participation. In addition, multiple regression analyses were carried out to identify the factors affecting physical activity by gender and exercise participation. All statistical analyses were performed using SPSS Win $23.0(p<.05)$.

\section{Results}

\section{Differences in psychological variables and physical activity by gender and the level of exercise participation}

$<$ Table $1>$ presented the differences in physical activity and psychological variables by gender and the level of exercise participation. The findings indicated that male students showed significantly higher scores on self-efficacy, exercise adherence, health risk perceptions, and physical activity than their female peers. Meanwhile, female students had significantly higher on exercise knowledge and cons than males. In addition, there are significant differences in selfefficacy, exercise adherence, pros, health risk perception, and physical activity between the level of exercise participation.

\section{Relationships between physical activity and psychological variables by gender and the level of exercise participation}

Before performing the multiple regression analysis, the correlation analysis between physical activity and psychological variables was carried out. The variables that did not significantly correlate with physical activity were deleted in the multiple regression analysis. <Table $2>$ showed the result of a multiple regression analysis conducted to identify the variables influencing on physical activity by gender and the level of physical activity participation. Results indicated that male students' moderate and strenuous physical activity was significantly explained by exercise adherence $(\beta=.42, \mathrm{p}<.001)$ and $\operatorname{pros}(\beta=.16, \mathrm{p}<.001)$. Meanwhile, a total physical activity was significantly influenced by exercise adherence $(\beta=.47$, $\mathrm{p}<.001)$. For female students, exercise self-efficacy $(\beta=.14$, $\mathrm{p}<.05)$, cons $(\beta=-.16, \mathrm{p}<.01)$, and exercise adherence $(\beta=.23$, $\mathrm{p}<.001)$ were significant in explaining a total physical activity.

Furthermore, results showed that the psychological variables had significant influences on physical activity according to the level of physical activity participation, In specific, cons $(\beta=-.25, \mathrm{p}<.01)$ and others-health risk perception $(\beta=.20, \mathrm{p}<.05)$ were significant in explaining the total physical activity of the nonexerciser group. For the intermittent exercise group exercise adherence $(\beta=.28, p<.001)$ and cons $(\beta=-19$, $\mathrm{p}<.01$ ) were influential factors on the total physical activity. In the regular exercise group the total physical activity was significantly influenced by exercise adherence $(\beta=.42, \mathrm{p}<.001)$, and $\operatorname{pros}(\beta=.17, \mathrm{p}<.05)$.

\section{Discussion}

More than $80 \%$ of young people worldwide have been failed to involve the recommended physical activity, and even one in four adults is not participating in any types of physical activity [31]. Considering the limited use of sports facilities in the aftermath of the Covid-19, it is hard to be optimistic that physical activities will continue to increase based on the recent increase in Korea's participation rate. However, in this period leading up to the early adulthood, healthy lifestyles also affect later habits, so continuous attention and effort are needed to make physical activities a habit. In response, this study sought to identify differences in exercise knowledge, health risk perception, exercise self-efficacy, exercise adherence, physical activity pros/cons, and physical activity difference, then verify the effects of these psychological factors on their physical activities.

The current study showed that physical activity or various cognitive and psychological factors differed depending on gender. Male students responded more to physical activity, exercise self-efficacy, physical activity pros, exercise adherence, and health risk perception than female counterparts, while females responded more to physical activity cons [32]. These differences could also be seen from the results of the identification of factors affecting physical activity by gender. Both male and female students had the greatest influence of exercise adherence on physical activities, but in the case of female students, physical activity cons and exercise self- 
Table 2. Results of regression analysis between psychological variables and physical activity

\begin{tabular}{|c|c|c|c|c|c|c|c|c|c|c|c|}
\hline group & $\begin{array}{l}\text { Dependent } \\
\text { variable }\end{array}$ & $\begin{array}{l}\text { Independent } \\
\text { variable }\end{array}$ & B & SD & $\beta$ & $t$ & $p$ & VIF & $R^{2}$ & $\operatorname{adj} R^{2}$ & $F$ \\
\hline \multirow{6}{*}{$\begin{array}{l}\text { M } \\
\mathrm{a} \\
\mathrm{I} \\
\mathrm{e}\end{array}$} & \multirow{3}{*}{$\begin{array}{l}\text { total } \\
\mathrm{PA}^{+}\end{array}$} & \multirow{3}{*}{4} & \multirow{3}{*}{783.88} & \multirow{3}{*}{101.72} & \multirow{3}{*}{.47} & \multirow{3}{*}{7.71} & \multirow{3}{*}{.00} & \multirow{3}{*}{1.00} & .22 & .22 & $59.39^{* * *}$ \\
\hline & & & & & & & & & \multicolumn{3}{|c|}{ Durbin-Watson } \\
\hline & & & & & & & & & \multicolumn{2}{|c|}{1.81} & \\
\hline & \multirow{3}{*}{$\begin{array}{l}\text { Moderate \& } \\
\text { strenuous PA }\end{array}$} & 4 & 642.04 & 95.67 & .42 & 6.71 & .00 & 1.03 & .22 & .21 & $29.65^{* * *}$ \\
\hline & & & & & & & & & \multicolumn{3}{|c|}{ Durbin-Watson } \\
\hline & & 2 & 509.60 & 196.55 & .16 & 2.59 & .010 & 1.03 & 1.82 & & \\
\hline \multirow{7}{*}{$\begin{array}{l}\mathrm{F} \\
\mathrm{e} \\
\mathrm{m} \\
\mathrm{a} \\
\mathrm{l} \\
\mathrm{e}\end{array}$} & \multirow{3}{*}{$\begin{array}{l}\text { total } \\
\mathrm{PA}^{+}\end{array}$} & 4 & 274.74 & 69.66 & .23 & 3.94 & .00 & 1.15 & .16 & .15 & $17.16^{* * *}$ \\
\hline & & 3 & -482.05 & 183.31 & -.16 & -2.63 & .01 & 1.18 & \multicolumn{2}{|c|}{ Durbin-Watson } & \\
\hline & & 1 & 445.96 & 186.09 & .14 & 2.40 & .02 & 1.18 & \multicolumn{2}{|c|}{1.81} & \\
\hline & \multirow{4}{*}{$\begin{array}{l}\text { Moderate \& } \\
\text { strenuous PA }\end{array}$} & 4 & 200.37 & 53.38 & .22 & 3.75 & .00 & 1.18 & \multirow{2}{*}{.16} & \multirow{2}{*}{.15} & \multirow{2}{*}{$13.09^{* * *}$} \\
\hline & & $6-1$ & -144.55 & 53.38 & -.15 & -2.72 & .01 & 1.04 & & & \\
\hline & & 1 & 337.41 & 142.22 & .14 & 2.37 & .02 & 1.20 & Dur & Natson & \\
\hline & & 3 & -277.22 & 140.14 & -.12 & -1.98 & .05 & 1.19 & 1.98 & & \\
\hline \multirow{6}{*}{ A } & \multirow{3}{*}{$\begin{array}{l}\text { total } \\
\mathrm{PA}^{+}\end{array}$} & 3 & -615.29 & 201.35 & -.25 & -3.06 & .00 & 1.01 & .09 & .08 & $7.24^{* *}$ \\
\hline & & & & & & & & & \multicolumn{3}{|c|}{ Durbin-Watson } \\
\hline & & $6-2$ & 197.01 & 78.55 & .20 & 2.51 & .01 & 1.01 & 2.10 & & \\
\hline & \multirow{3}{*}{$\begin{array}{l}\text { Moderate \& } \\
\text { strenuous PA }\end{array}$} & \multirow{3}{*}{4} & \multirow{3}{*}{58.48} & & & & & & .039 & .032 & $5.799^{*}$ \\
\hline & & & & 24.29 & .20 & 2.41 & .02 & 1.00 & Dur & Natson & \\
\hline & & & & & & & & & 1.69 & & \\
\hline & & 4 & 313.55 & 74.56 & .28 & 4.22 & .00 & 1.02 & .13 & .12 & $14.44^{* * *}$ \\
\hline & $\begin{array}{l}\text { total } \\
\mathrm{PA}^{+}\end{array}$ & & & & & & & & Dur & Natson & \\
\hline$R$ & & 3 & -392.51 & 141.19 & -.19 & -2.78 & .01 & 1.02 & 1.79 & & \\
\hline$D$ & & 2 & 347.20 & 118.86 & .20 & 2.92 & .00 & 1.00 & .07 & .06 & $7.84^{* *}$ \\
\hline & $\begin{array}{l}\text { Moderate \& } \\
\text { strenuous PA }\end{array}$ & & & & & & & & Dur & Natson & \\
\hline & & 3 & -280.90 & 118.86 & -.18 & -2.59 & .01 & 1.00 & 1.85 & & \\
\hline & & 4 & 935.13 & 165.49 & .42 & 5.65 & .00 & 1.03 & .23 & .22 & $21.15^{* * *}$ \\
\hline & $\begin{array}{l}\text { total } \\
\mathrm{PA}^{+}\end{array}$ & & & & & & & & Dur & Natson & \\
\hline 0 & & 2 & 863.00 & 387.22 & .17 & 2.23 & .03 & 1.03 & 2.03 & & \\
\hline 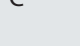 & & 4 & 731.24 & 151.18 & .37 & 4.84 & .00 & 1.03 & .21 & .19 & $18.55^{* * *}$ \\
\hline & $\begin{array}{l}\text { Moderate \& } \\
\text { strenuous PA }\end{array}$ & & & & & & & & Dur & Natson & \\
\hline & & 2 & 1004.59 & 353.74 & .21 & 2.84 & .01 & 1.03 & 1.87 & & \\
\hline
\end{tabular}

${ }^{* * *} p<.001,{ }^{* *} p<.01,{ }^{*} p<.05$

A: nonexerciser; B: intermittent exerciser; C: regular exerciser; 1: self-efficacy; 2: pros; 3: cons; 4: exercise adherence; 5: exercise knowledge; 6: health risk perception(6-1: Self, 6-2 : others); 7: physical activity

+ Sum of mild, moderate, and strenuous physical activity

efficacy were also influential factors. According to a study by Kim, Park, and Yoo [33], it was confirmed that women in 20s responded more to exercise inhibitors in various areas than middle-aged women, and that they were more "fearful" about their activities, which can be interpreted in conjunction with the results of this study. In other words, it is important to interpret the physical activity cons positively and to have a "can do" mindset about physical activity, although the exercise adherence is important for female students' physical activities.

However, Jo and Song [34] interpreted the physical fatigue 
perceived as a lack of knowledge to negatively interpret signals caused by physical activity. It is also interesting in this study that exercise knowledge and health risk perception, which correspond to cognitive variables, are not influencing variables. Park and Kim [2] suggested that exercise knowledge and health risk perception may not be important factors for college students unlike middle-aged participants [17].

From these findings, college students may be less aware of the cognitive aspects such as exercise knowledge or health risk perception. However, for groups that do not participate exercise, the importance of information about the risks that may arise from not engaging in physical activity is given by the fact that health risk perception of others affects physical activity. However, it is revealed that health risk perception seems to be less influential to college students than middleaged adults [17] or meta-analysis results [35].

The physical activity intervention strategy has currently provided significant information on physical activity knowledge and benefits in the early stages, while making it possible to perceive physical activity pros and cons [12]. However, some studies argued the different opinions, demonstrating that gender and the level of physical activity participation were more significant predictors rather than the transtheoretical model constructs to explain physical activity. Therefore, it needs to be continued in order to gain more empirical knowledge from evidence-based investigations applying the theory-based interventions with some other variables such as gender, age and the level of physical activity participation.

\section{Acknowledgments}

This research was supported by the Ministry of Education of the Republic of Korea and the National Research Foundation of Korea (NRF-2016S1A5B5A02024293).

\section{Conflicts of Interest}

The authors declare no conflict of interest.

\section{References}

1. Kim SH, Byun WT, Lee JW. Validation of the Ego-Resiliency Scale to Stages of Exercise Behavior Change through Rasch Model. The Korean Journal of Measurement and Evaluation in Physical Education and Sport Science. 2012; 14(1): 69-82

2. Park IK, Kim YH. The Effect of Exercise Knowledge and Health Risk Perception on Physical Activity in College Student. The Korean Journal of Sport. 2019; 17(2):163177.

3. Kim SM, Kim SO. Comparison of Knowledge of Nursing Students toward Cancer, Attitude and Preventive health behavior according to Clinical Experience. Asia-pacific Journal of Multimedia Services Convergent with Art, Humanities, and Sociology. 2019; 9(2):655-664.

4. Yang YK. Factors Influencing Preventive Health Behaviors for Cancer in Undergraduates. J Korean Acad Fundam Nurs. 2020; 22(1):59-68.

5. Lee JY, Seo B, Kang SK. Development of Exercise Participation - Measurement Tool using Health Belief Model . Korean Journal of Measurement and Evaluation in Physical Education and Sports Science. 2012; 14(2):51-60.

6. Stephan Y, Boiche J, Trouilloud D, et al. P. The relation between risk perceptions and physical activity among older adults: A prospective study. Psychol Health. 2011; 26:887-897.

7. Oh EK, Lee HH. A health voucher intended for the elderly Exploring the Determinants of Health-related Quality of Life. Korean J Sport. 2011; 17(2):199-208.

8. Kim YH, Kosma M. Psychosocial and environmental correlates of physical activity among Korean older adults. Res Aging. 2013; 35:750-767.

9. Park IK, Kim YH. College Students' Stage of Change, Exercise Self-Schemata, and Exercise Adherence Intention Related to Weekly Exercise Time. Korean J Sport Psychol. 2013; 24(2):89-102.

10. Banting LK, Dimmock JA, Lay BS. The role of implicit and components of exercise self-schema in the prediction of exercise behavior. Psychol Sport Exerc. 2009; 10:80-86. 
11. An DJ, Kim YH, Kang SJ. Effects of exercise information using social network service(SNS) on physical activity and psychological variables among inactive college students. Korean J Sport Sci. 2020; 31(2):189-201.

12. Blissmer B, McAuley E. Testing the requirements on stage of physical activity among adults: The comparative effectiveness of stage-matched, mismatched, standard care, and control interventions. Ann Behav Med. 2002; 24:181-189.

13. Kim YH, Kim HS, Kang SJ. The Effect of Obesity Management Program Based on Physical Activity and Psychological Modification on Body Mass, Physical Activity and Its Related Psychological Variables. Korean J Sport Psychol. 2013; 24(1):193-208.

14. Marcus BH, Forsyth LH. Motivating People to Be Physically Active. J Sport Psychol. 2003; 17:375-377.

15. Ko JH. The Relationship of Health Knowledge on Adolescent Sports Participation. Master's Thesis, Sangmyung University, Seoul, 2010.

16. Lee CH. College students' partipacipation in physical activity course and their knowledge of exercise guidelines. Master's Thesis, Yonsei University, Seoul, 2006.

17. Kim YH, Kang SJ, Park IK. Health Risk Perception according to Gender and the Physical Activity Level in Middle- Aged Adults. Korean J Sport Psychol. 2016; 27(3):57-69.

18. Song JM. Middle school teachers' knowledge and behavior of fitness exercise. Master's Thesis, Yonsei University, Seoul, 2005.

19. Park IK, Kang SJ. Physical Activity and Relationship with Exercise Self-Schema, Exercise Imagery and Exercise Self Efficacy in Adults. Korean J Sport Psychol. 2016; 27(1):21-34.

20. The IPAQ group. Guidelines for the data processing and analysis of the international physical activity questionnaire(IPAQ). 2011.

21. Oh JY, Yang YJ, Kim BS, Kang JH. Validity and reliability of Korean version of international physical activity questionnaire (IPAQ) short form. J Korean Acad Fam Med. 2007; 28,532-541.
22. Kim SY, Oh KS, Shin DW et al. The association of physical activity and sleep duration with incident anxiety symptoms: A cohort study of 134,957 Korean adults. J Affect Disord. 2020; 265:305-313.

23. Morrow JR, Jackson AW, Bazzarre TL, et al. A one-year follow-up to physical activity and health. Am. J. Med. 1999; 17:24-30.

24. Whalen CK, Henker B, O'Neil R, et al. Optimism in children's judgements of health and environmental risks. Health Psychol. 1994; 13:319-325.

25. Kim YH. Preliminary findings on Korean adolescents' role in lay risk perception. RISK, Health, Safety \& Environment, 2007; 4(3):189-212.

26. Shin YH, Jang HJ, Pender NJ. Psychometric evaluation of the exercise Self-Efficacy Scale among Korean adults with chronic diseases. Res Nurs Health. 2001; 24:68-76.

27. Plotnikoff RC, Brez S, Hotz SB. Exercise behavior in a community sample with diabetes: Understanding the determinants of exercise behavioral change. Diabetes Educ. 2000; 26:450-459.

28. Kim YH, Cardinal BJ, Lee JY. Understanding exercise behavior among Korean adults: A test of the transtheoretical model. Int J Behav Med. 2006; 13:295303.

29. Ajzen I. The theory of planned behavior. Organ Behav Hum Decis Process. 1991; 50(2):179-211.

30. So YH. Relationship among Leisure Satisfaction, Outcome Expectations, Exercise Adherence and Intention to Dropout of Life Sports Participants. The Korean Journal of Physical Education. 2013; 52(3):363-378.

31. World Health Organization(WHO). Physical activity. 2018; https://www.who.int/ newsroom/fact-sheets/detail/ physical-activity. (Accessed Aug 20, 2020).

32. Leslie E, Fotheringham MJ, Owen N, et al. Age-related differences in physical activity levels of young adults. Med Sci Sports Exerc. 2001; 33(2):255-258.

33. Kim YR, Park SH, Yoo YJ. The Regular Exercise between Women in their 20's and middle-aged Women on Subfactors of Perceived Exercise Barrier Factors. Korean J Sports Sci. 2011; 20(3):1445-1456.

34. Jo JH, Song GJ. Rasch Calibration and Evaluation of 
Perceived Barriers to Exercise among College Women. Korean Journal of Measurement and Evaluation in Physical Education and Sports Science. 2002; 4(2):1-13.

35. Brewer NT, Chapman GB, Gibbons FX, et al. Meta-analysis of the relationship between risk perception and health behavior: The example of vaccinations. Health Psychol. 2007; 26:136-145. 